\title{
ALCOHOLISM AS A PROFESSIONAL DISEASE OF THE REPRESENTATIVES OF JUSTICE
}

DOI: 10.36740/WLek202012238

\author{
Oksana Z. Khotynska-Nor', Lidiya M. Moskvych ${ }^{2}$ \\ 'TARAS SHEVCHENKO NATIONAL UNIVERSITY OF KYIV, KYIV, UKRAINE \\ ${ }^{2}$ YAROSLAV MUDRYI NATIONAL LAW UNIVERSITY, KHARKIV, UKRAINE
}

\begin{abstract}
The aim: The purpose of the research is to summarize the leading experience of European countries on the protection and prevention of the alcoholism problem among judges, attorneys and prosecutors as representatives of justice.

Materials and methods: The subject under discussion has been considered based on sources on this issue (scientific publications, legal acts, decisions of judicial and quasijudicial institutions), using the method of content analysis, comparative and contrastive, analytical and biblio-semantic methods.

Conclusions: Analysis of existing statistics as well as decisions of the disciplinary bodies of justice indicates the predisposition of justice representatives to alcohol dependency, which is caused by a number of reasons. Based on medical research, it is substantiated that stress is the determining factor in prompting a justice officer to use alcohol as a means capable of exerting an antidepressant effect. But in addition to quickly de-stress, alcohol is attractive for its availability. We refer such availability as: financial, social and psychological, corporate, territorial, legislative one. It is argued that among the representatives of justice alcoholism has a harmful effect not only on their health. It has a negative impact on professional discipline and is fraught with de-ethicalization of representatives' of justice behavior. The alcohol dependence of justice officials can cause doubts on their competence, hold them accountable and undermine public confidence in the credibility of justice.
\end{abstract}

KEY WORDS: alcoholism, litigation stress, justice, alcohol addiction

Wiad Lek. 2020;73(12 p. II):2934-2939

\section{INTRODUCTION}

According to the World Health Organization, alcohol consumption and its level is one of the most important public health problems worldwide. The latest data indicates that alcohol abuse is the reason for 1 in 20 deaths [1], and is one of the most common mental disorders, with a prevalence of 8 to 14 percent [2], not to mention other negative effects on human health and behavior, as well as the productivity and effectiveness of various spheres of activity.

Alcoholism has no social, gender or financial barriers, covering different segments of population. Nevertheless, large-scale studies show that the level of alcohol consumption directly depends on the profession and industry of employment [3]. Activities related to the administration of justice are one of the indicative ones in this sense. There is some evidence that people involved in this work environment experience alcohol problems that are dangerous, harmful, or otherwise correlate with alcohol consumption disorders at a higher rate than other professional groups. As it turned out, $21 \%$ of attorneys have problems with alcohol, $28 \%$ of them suffer from depression of some degree, and 19\% have signs of anxiety disorder [4]. Research from Australia has shown that $30.6 \%$ of court officials and 32\% of attorneys are at risk for problem of alcohol drinking [5].

Alcohol abuse, whether in or outside the workplace, has a negative impact on work, leading to consequences such as health problems, long-term disability, decreased productivity and presentability, team conflicts and an unstable work environment, accidents at workplace, reputational damage [6]. It has significant economic and social impact in justice sphere. The inability to fulfill professional duties causes a redistribution of colleagues' workload, which reduces the productivity of their work, and as a result - ineffective time and human resources usage. The public interest is the ability of a judge, an attorney, a prosecutor to adequately assess the circumstances of the case entrusted to one and to make objective decisions, as well as the adequate behavior of these persons in a trial and outside it. The public opinion on the latter directly affects the credibility of justice among the population [7].

Alcohol is the cause in many cases of disciplinary proceedings initiated for violation of legal and ethical norms by representatives of justice system, damage to the client and harm to profession's credibility.

Due to the potentially serious medical, social, and economic consequences of alcoholism in the sphere of justice, its assessment needs to be detailed.

\section{THE AIM}

Our study is aimed at providing readers with an overview of the reasons that are highly likely to contribute to the development of alcoholism of justice's representatives, 
as well as to demonstrate the consequences of its impact on the profession. We will also offer a system of methods aimed at preventing and combating alcoholism in this professional environment.

\section{MATERIALS AND METHODS}

We use statistics of the World Health Organization, the Legal Profession Assistance Conference, as well as information and decisions by professional bodies in the justice sphere in the United States and Ukraine (ABA, the Highest Council of Justice). We also use data from medical and other researches, analytical materials and scientific publications by the USA, Canada and Australia with open access, reflecting the results of studying the problems of litigation stress and, as a result, alcoholization of judges, attorneys, and prosecutors. The article is based on the dialectical method, which made it possible to study the essence of litigation stress and alcohol dependence, the risks of which it develops. Statistical, structural-logical and analytical methods were used to study the causal connections between the work conditions of justice officials, litigation stress and alcohol.

\section{REVIEW AND DISCUSSION}

\section{Causes and risks of alcoholism development in justice.}

There are several theories regarding the reasons for the development of representatives' of justice alcohol addiction.

According to one version, alcohol is part of the corporate culture of lawyers. Maintaining formal and informal corporate ties is accompanied by events where alcohol is always present, giving an atmosphere of complacency and relaxation.

Alternatively, it is also assumed that alcohol problems accompany lawyers from their student days. After entering law school (having high level of life satisfaction and stable mental health at that time), law students experience significant increases in anxiety and depression during their first year of student's life. According to ABA, law students are ones of the most demoralized and depressed among all students, a quarter of them fall into the category of risk of developing alcoholism [8]. There are many reasons for it: heavy load, high competition level, lack of social connection feeling, the initially pessimistic and adversarial nature of law, the Socratic methods of teaching it, external motivation to study it, in which the emphasis is on future dividends associated with the profession, and which depend on academic performance and rating $[9 ; 10]$. Trying to cope with stressful situations on their own, law students resort to alcohol, transferring this practice to their future professional activities.

Nevertheless, most studies associate high rates of alcohol addiction among representatives of justice with the stress they experience due to the specifics of the professional environment (litigation stress).

Features of the profession and professional stress. The medical literature considers litigation stress as a process and result of exposure by a set of stressors, the nature of which is diverse. They can be of objective and subjective origin, depending on physical or psychosocial factors. Their influence can negatively affect human health and lead to serious psychological and behavioral problems. Although in many respects the appearance and level of stress depends on a person's internal attitudes and his/her reaction to stressors, in the justice system a huge role is played not only by work conditions, but by the specifics of the professional environment - the litigation itself. It acts as an objective condition, the readiness for the perception of which must be established at the stage of preparation for the profession.

The adversarial nature of the trial, in which a judge, an attorney and a prosecutor are involved by the nature of their activities, is based on a conflict, which emotionally responds with a feeling of irritation, anger, fear, and being worried. The conflict potential of judicial sphere is complemented by the need to constantly search for atypical solutions in a limited time. It entails constant mental stress. In addition, each of the representatives of justice is responsible for the decision he/she makes, for the chosen defense tactics or line of prosecution, often at the risk of feeling dissatisfaction, resentment, grief or accusations against one from the disgruntled participants of the trial.

They must control their feelings of empath, hatred, irritation, anger and be restrained in their reflection. Constant emotional control is fraught with stress. Scientists have proven that, for example, controlled empathy is the most dangerous and stressful type of it. It itself includes neurological activity. When a person engages in automatic empathy, tension is easily released. Both brains' hemispheres work to achieve homeostasis. This process is interrupted while controlled empathy [11].

In addition, the litigation is aimed at solving the problems of people whose life stories can be traumatic. This is especially true for criminal, family, juvenile cases. Constant involvement in the traumatic events of someone else's life is fraught with vicarious trauma for the representatives of justice (the terms "compassion fatigue", "burnout", secondary trauma could also be used) [12]. Professionals who consistently work with traumatized people and traumatic situations, experience the same trauma symptoms, including worrying, avoidance, numbness, and constant excitement. They can also experience extreme vigilance, hopelessness, anger and cynicism, insomnia, fear, guilt, chronic exhaustion and physical ailments [13]. The majority of judges and lawyers ascertained the presence of these feelings in various combinations $[14 ; 15]$.

Social factors. All representatives of justice are bound by the requirements of ethical codes, which establish behavioral rules not only at work, but also outside it. The high social status of their profession entails increased public attention to their personality, demeanor and lifestyle. It causes social distance and puts a lot of pressure making them to maintain an ideal image.

In countries with a low level of trust to judiciary system, such as Ukraine, the lack of social support is a powerful stressor for representatives of justice. It also affects their social isolation and generates a decrease in self-esteem, negatively affects confidence and work efficiency [16]. 
It is still the totality of the features of the trial and the professional roles of its key players (which require a high level of responsibility and emotional self-control, self-restraint and tension) is the factor which initially create favorable conditions for the onset and development of stress and depression. The natural desire to relax leads a person to find effective remedies. One of them is alcohol, which blocks inhibitory brain cells, making the consumer feel relaxed and relieving anxiety [17].

Why it is still alcohol (more than drugs or, for example, physical activity, which can also positively influence stress) is becoming the choice of the representatives of justice? There are several reasons for this.

Alcohol as a stress reliever and its availability. Among the possible means of relieving stress and feelings of anxiety, alcohol compares favorably with its varied "availability."

Several studies have shown that alcohol in small doses can improve the performance of complex cognitive tasks aimed at solving problems in a stressful situation [18]. Although the interconnection between alcohol and stress is determined by many factors (genetic, individual, situational, gender, age ones), recent experiments have shown that alcohol has a similar effect to mild antidepressants. It was found that a single intake of alcohol affects in the way of the same biochemical mechanism as the "rapid antidepressants" from the group of NMDA glutamate receptor antagonists. Alcohol promotes long-term neuroadaptive changes that can alleviate the symptoms of depression, often mentioned in the self-medication hypothesis. Acute ethanol exposure produced long-term antidepressant and anxiolytic behavior [19].

During the period of the stressor's action, endogenous opioid peptides (endorphins) are produced in the brain, which help to minimize adverse psychoemotional effects. However, in the subsequent period, there is a deficiency of endorphins due to their excessive release during the action of the stressor, i.e. the syndrome of "recoil" develops. Endorphin deficiency is accompanied by anxiety and depression symptoms. According to the endorphin compensation hypothesis, people consume alcohol after experiencing a traumatic experience in order to increase the level of endorphins in the brain and their mood in that way. As maintaining high levels of endorphins requires more and more alcohol, a vicious circle gradually forms, which could lead to the development of being alcohol addicted. The endorphin compensation hypothesis explains why, in most cases, alcohol is consumed sometime after a stressor's impact, and not during it itself [20].

Thus, alcohol creates the illusion of a quick stress relief, which is in line with the expectation of quick stress relief. Although in the medical literature there is enough information on the existence of feedback, when alcohol abuse causes stress, depression, addiction, forming a vicious circle. However, alcohol is attractive because, unlike antidepressants, it does not require a doctor's appointment, diagnosis or prescription. Alcohol, unlike drugs or medicines, is available for sale with certain age restrictions. A person does not need to go far or contact specialized institutions or certain people in order to buy it. Among the possible psychoactive substances, it is financially affordable, diverse and could also satisfy a person's taste preferences. The state, regulating the alcohol market does not ban its sale and consumption. The fact of drinking alcohol doesn't violate any legal norms.

The culture of drinking alcohol is woven into the system of social relations. It is not condemned, unlike drug addiction. Alcohol abuse in society is characterized by a condescending attitude. Moreover, in some countries, such as Russia, the alcoholization of society is connected with historically strong traditions and lifestyle. The existence of a large number of customs that serve as a reason for drinking alcohol, which are not easy to eradicate, since traditions are an element of social reality, leads to population's loyalty to alcohol. That is, alcohol is psychologically and socially available. This factor is reinforced by the corporate culture of alcohol consumption among lawyers, which we have already mentioned.

Another argument in favor of alcohol, which in most cases is preferred by representatives of justice, is the difficulty of diagnosing alcoholism. Even in a medical conditions, the screening rate for alcohol consumption remains below 50 percent [2]. Among the representatives of justice, it is aggravated by the fact that it is not customary to talk about the problem of alcohol addiction. It is primarily connected with reputational risks for professional activity. Representatives of aid programs to lawyers note that the reluctance to admit their alcohol addiction is associated not only with perfectionism, but also with the fear of damaging their reputation, losing the trust of colleagues and clients, and losing their license and work [21]. And these fears are absolutely justified.

Impact on work and possible consequences. Alcoholism, as well as other addictions to psychoactive substances, cause doubt on their compatibility with the professional status of the representatives of justice. And it's not only about its clinical reflections (disorders of thinking, hypochondria, persecution mania, low self-esteem, anxiety, depression, impulsiveness, alcoholic degradation of personality) [22], which negatively affect the productivity and efficiency of any activity. Any addiction distorts the normal flexibility of a person's behavior towards dehumanized compulsive behavior and decontrolling [23]. Addiction weakens the neural mechanisms responsible for making reasonable decisions, and a person moves from independent behavior to automatic sensory-controlled behavior [24]. A person loses the ability to perceive reality adequately, self-regulation of his behavior, there is a tendency to an asocial way of life. Ethical norms are losing their regulatory effect. And it is unacceptable for the professional environment in the administration of justice.

Alcohol addiction, affecting the emotional, mental, and physical state of the representatives of justice, could rise a question on their competence. It is directly mentioned in corporate ethics acts that regulate professional activity of lawyers. The commentary on the Bangalore Principles of Judicial Conduct states that "the competence of a judge can 
narrow, or cause doubts by the effects of drugs or alcohol use ..." [25].

Practice shows that attorneys suffering from addiction are most often prosecuted for wasting and embezzlement of client funds. According to ABA, in 2013, 936 attorneys were convicted of substantiated claims [26]. The link between alcoholism and professional negligence and misconduct is confirmed by a report prepared by the Legal Profession Assistance Conference [27]. Studies in Canada and in the United States estimate that approximately $60 \%$ of discipline prosecutions involve alcoholism. Similarly, something over $60 \%$ of all malpractice claims involve alcohol abuse. More significantly, a recent study has suggested that $90 \%$ of serious disciplinary matters involve alcohol abuse. It is confirmed by the results of previous studies, according to which " 50 to 70 percent of disciplinary cases are related to alcoholism." Its authors concluded that the true rates are significantly higher, given the mystery that shrouds such abuse [28].

Moreover, in US disciplinary practice alcoholism is a factor that determines one of three approaches to bring judges to liability: the punitive approach, the rehabilitative approach, or the mitigating factor approach [29].

It should be admitted that there are no such studies in Ukraine. However, disciplinary practice in this direction is extensive, although not generalized. An illustrative example of the connection between alcohol abuse and violation of ethical professional standards and responsibility is the case of a judge of the Supreme Court. This case is very interesting for its circumstances.

In March 2019, a judge, who at that time had not yet entered office, was detained and brought to administrative responsibility for driving while intoxicated. While hearing the administrative case in court, he only denied the fact of driving a car. These words were refuted by various evidence, including the testimony of several witnesses. Thus, he lied, which was established by the courts of various instances, in order to avoid responsibility. He had already fully acquired the status of a judge at the time of the trial. It was still the lie, that the Supreme Court judge resorted to, that triggered the disciplinary proceedings. As a result, the judge's dismissal was initiated. At the same time, the disciplinary body emphasized that the status of a judge imposes on a person an additional burden of responsibility for behavior, including behavior in the past. "Maintaining high standards of behavior requires a judge to avoid creating the impression of inappropriate behavior both in office and in private life. A judge must be aware that he/she represents the judicial power of the state and must not allow behavior on his/her part that could harm the authority of justice." Without assessing the judge's behavior before his appointment as a Supreme Court judge, the disciplinary body concluded that "the provision by a judge of the Supreme Court of false information in court that did not correspond to the factual circumstances of the case in order to avoid responsibility for his actions indicates a violation of high standards of ethical behavior of a judge and cannot be justified by a person's right to defense. ... being a judge of the Supreme Court, which is the highest court of the court system, he couldn't not to realize that his behavior significantly undermines the authority of justice and public confidence in court, as it affects the main elements of the judge's ability to perform the work entrusted to him as a judge on administration of justice... "[30].

This example shows that the primary reason for the de-ethicalization of the judge's behavior was his alcohol abuse. We can draw two conclusions from it. Firstly, the ethics of justice officials can be retroactive. Secondly, alcohol can have a prospective effect on the discipline and responsibility of these persons.

It is still the social side that makes the alcoholization of justice representatives to be dangerous at the state level, in contrast to other professions, where it is only about human health. Therefore, it is very important to develop and to implement a set of measures aimed at preventing and combating alcoholism in the administration of justice sphere.

Methods of combating alcoholism in the justice sphere. Considering the specifics of the status and professional sphere of justice, which we mentioned, its representatives need support that can prevent alcoholization and minimize its negative consequences for both the individual and society. The methods should be of a comprehensive nature (psychological, organizational, rehabilitation, social security) and be implemented at different levels.

State approach. First, the state, which exercises its power through the means of justice, should be interested in ensuring that the health of representatives of justice sphere couldn't be undermined by alcohol addiction. To do this, it should, in its own way - through legislative regulation, provide for measures that are able, first, to reduce the influence of stressors, as a result of which stress arises, which induces alcohol drinking. For example, there should be a regulated workload on judges, which can be ensured not only by mathematical calculations, but also by appropriate organizational measures: timely filling of vacancies, introduction of clear procedural rules, and ensuring appropriate work conditions. For the purpose of timely diagnosis of the disease, it is advisable at the legislative level to provide for the obligation of representatives of justice to undergo a medical examination by a narcologist annually [7]. In matters of discipline and responsibility, priority should be given to the rehabilitation approach [29]. It is based on the possibility of providing a lawyer with a probationary period with the obligatory condition of treatment and a sober lifestyle. It is most beneficial both for the professional facing the problem of alcohol, and for the society, which will continue to benefit from his/her experience and knowledge, and for the state, which will incur less rehabilitation costs than training a new lawyer. As a measure of social protection of justice officials who have suffered from alcohol addiction, it is permissible to provide for the possibility of dismissal from office due to illness, and not within the framework of disciplinary action.

An important component of state policy should be the initiatives aimed at increasing the credibility level of representatives of justice in society, creating a high level of 
trust in them, which will contribute to the social support of these persons.

Corporate approach. Professional sphere offers just as many opportunities. Corporate level is more flexible, since the system of possible means of alcohol prevention and rehabilitation depends directly on the bodies of professional community.

It is imperative that each of the corporate communities (judges, attorneys, prosecutors) develop, implement and popularize assistance programs aimed at combating litigation stress and alcohol addiction. They should provide for psychological support, access to counseling and assistance. Such programs should be documented. They need to clearly outline the corporate policy on alcohol and other substance abuse, a statement of support for the mental and physical health of members of the professional community, resources and methods of such support. For example, a "hot line" can help to talk about the problem faced by a representative of justice, to get a consultation by a psychologist or an addiction specialist by phone. Particular attention should be paid to privacy issues. Its full provision is necessary in order to induce alcohol-addicted justice officials to ask for help. Part of such assistance programs should be cooperation with medical centers aiding in alcoholism treatment.

Special attention should be paid to educational activities among lawyers. Explanatory work should be carried out from the student's bench and strengthened during special training. To this end, the centers responsible for training judges, lawyers, prosecutors should include in their professional training programs such training, which is aimed at developing stress resistance, training in stress management skills and avoiding vicarious trauma. They should also ensure cooperation with specialists in this direction.

A local approach provides for a focus on the personality and workplace of justice representatives. It includes paying the attention by a lawyer to himself and by his/ her colleagues. Taking care of one's own health should be among the first human needs. Realizing a problem, finding resources to solve it, seeking help are a sign of strength, not weakness. In the workplace, it is possible to create conditions for shifting attention from alcohol to sports, which helps to overcome stress, having a positive effect on the emotional and physical condition of the individual. In court buildings, law firms and prosecutors' offices, it is advisable to provide areas for relaxation and active physical exercise. If possible, psychologist's offices should also operate for free psychological support and assistance. Special attention should be paid to the organization of working hours and the daily routine in which there should be a place for having a rest.

Of course, the mentioned measures are not exhaustive. After all, the mechanisms of combating alcoholism, including in the justice system, are very diverse. We can continue to talk about, for example, additional vacations, the institution of supervision or relaxation practices. But even the measures we have mentioned in this article are enough to assess the current situation in the field of counteracting alcoholism in such an important sphere for society. For example, in Ukraine, there is no comprehensive research of this problem, no legislative or corporate initiatives aimed at supporting and helping justice officers in counteracting the challenges of the profession.

\section{CONCLUSIONS}

Justice officials are one of the professional communities most vulnerable to stress, depression and alcohol addiction. Among the reasons contributing to alcoholism there are the corporate culture of lawyers, traditions formed during their education, litigation stress. It is still precisely in the desire to quickly relieve stress that representatives of justice resort to alcohol, which could have an antidepressant effect. Therefore, alcohol addiction appears as a result of self-treatment, which they resort to, considering the variety of alcohol availability: financial, socio-psychological, corporate, territorial, legislative. The causes of litigation stress are manifold and of subjective and objective nature. The latter includes the professional environment. The stressful nature of a conflict-based litigation creates conditions for the development of stress, vicarious trauma among the representatives of justice, which increases the risks of their alcohol addiction. Statistics and literature sources show a causal relationship of professional environment of justice $\rightarrow$ stress $\rightarrow$ alcohol. This makes it possible to further study alcoholism as an occupational disease of justice officers.

Alcohol dependence of representatives of justice is not only the result of the negative work conditions in the justice environment impact, but also has an effect, including a prospective one, on the discipline and responsibility of its representatives. Alcoholization of the justice sphere is dangerous not only for the health of its representatives. It is also fraught with de-ethicalization of the lawyer's behavior, causing doubts on one's competence, as well as undermining the credibility of justice in society and devaluation of moral principles. Overcoming the problem of alcoholization of representatives of justice requires an integrated approach and the adoption of measures of a psychological, organizational, rehabilitation, social security nature at different levels: state, corporate and local.

\section{REFERENCES}

1. World Health Organization. Global status report on alcohol and health 2018. Available from: https://apps.who.int/iris/bitstream/ handle/10665/274603/9789241565639-eng.pdf?ua=1 [reviewed 2020.08.18].

2. Enoch M-A., Goldman D. Problem Drinking and Alcoholism: Diagnosis and Treatment. American Family Physician. 2002; 65(3):441-448.

3. Bush DM, Lipari RN. Substance use and Substance use Disorder by Industry.URL: https://www.ncbi.nlm.nih.gov/books/NBK343542/

4. Krill PR, Johnson R, Albert L. The Prevalence of Substance Use and Other Mental Health Concerns Among American Attorneys. Journal of Addiction Medicine. 2016;10 (1):46-52.

5. Schrever C, Hulbert C, Sourdin T. The Psychological Impact of Judicial Work: Australia's First Empirical Research Measuring Judicial Stress and Wellbeing. Journal of Judicial Administration update. 2019; 28 (3):141-168. 
6. Gábor E, Kudász F. Substance use and work. Available from: https:// oshwiki.eu/wiki/Substance_use_and_work\#cite_note-24[reviewed 2020.08.18].

7. Moskvych LM, Khotynska-Nor $0 Z$, Biletska GA. Disease as interference for judge's profession. Wiadomosci Lekarskie. 2019; 72: 2501-2509.

8. The Path to Lawyer Well-Being: Practical Recommendations for Positive Change. 2017. p.7-11. Available from: https://www. americanbar.org/content/dam/aba/images/abanews/ThePathToLawyer WellBeingReportRevFINAL.pdf [reviewed 2020.08.18].

9. Skead N, Rogers S. Stress, anxiety and depression in law students: how student behaviors affect student wellbeing. Monash University Law Review. 2014; 40 (2):564-587.

10. Anna Huggins. Autonomy supportive curriculum design: A salient factor in promoting law students' wellbeing. University of New South Wales Law Journal. 2012; 35(3): 683-716.

11. Izzo E, Miller VC. Day After Day The Price You Pay: Managing Your Second - Hand Shock. 2008. USA: High Conflict Institute. p. 13-15.

12. Boscarino JA, Adams RE, Figley CR. Secondary Trauma Issues for Psychiatrists. Psychiatric Times. 2010; 27 (11): 24-26.

13. Wood Smith D. Secondary or Vicarious Trauma Among Judges and Court Personnel. Available from: https://www.ncsc.org/trends/monthlytrends-articles/2017/secondary-or-vicarious-trauma-among-judgesand-court-personnel [reviewed 2020.08.18].

14. Peter G. Jaffe et al. Vicarious Trauma in Judges: The Personal Challenge of Dispensing Justice. Juvenile and Family Court Journal. 2003; 54:1-9.

15. McQuiston, DE, Hooper, MD, Brasington, AE (2019) Vicarious trauma in the courtroom: Judicial perceptions of juror distress. The Judges Journal. 2019; 58(2): 32-35.

16. Miller MK, Reichert J, Bornstein BH et al. Judicial stress: the roles of gender and social support. Psychiatric Psychal Law. 2018; 25(4):602-618.

17. Valenzuela C. Alcohol and Neurotransmitter Interactions. Alcohol, Health \& Research World. 1997; 21 (2):144-148.

18. Sayette MA. Does Drinking Reduce Stress? Alcohol Research and Health. 1999; 23: 250-255.

19. Wolfe S., Workman E., Heaney C. et al. FMRP regulates an ethanoldependent shift in GABABR function and expression with rapid antidepressant properties. Nature Communication. 2016; 7 (12867). doi: $10.1038 /$ ncomms 12867 .

20. Razvodovskij Yu.E. Alkogol' i stress. [Alcohol and stress] Mediczinskie novosti. 2006;10:18-22.(Ru).

21. Ward SF. How can attorneys get help without harming their careers? (Podcast with transcript). 2015. Available from: https://www. abajournal.com/news/article/podcast_monthly_episode_60 [reviewed 2020.08.18].

22. Edwards, G. The alcohol dependence syndrome: A concept as stimulus to enquiry. British Journal of Addiction, 1986; 81(2):171-183.

23. Sellman, D. The 10 most important things known about addiction. Addiction. 2010;105(1):6-13.

24. Bettinardi-Angres K, Angres DH. Understanding the Disease of Addiction. Journal of Nursing Regulation. 2010;1(2):31-37.
25. Commentary on the Bangalore Principles of Judicial Conduct. United Nations. Office on Drugs and Crime. September 2007. Available from: https://www.unodc.org/documents/nigeria/publications/ Otherpublications/Commentry_on_the_Bangalore_principles_of_ Judicial_Conduct.pdf [reviewed 2020.08.18].

26. Ward SF. Lawyers who self-medicate to deal with stress sometimes steal from those they vowed to protect. 2015. Available from: https://www. abajournal.com/magazine/article/lawyers_who_self_medicate_ to_deal_with_stress_sometimes_steal_from_those?utm source=internal\&utm_medium=navigation\&utm_campaign=most_ read [reviewed 2020.08.18].

27. Drug and Alcohol Abuse \& Addiction in the Legal Profession. By the Legal Profession Assistance Conference. Available from: http://www. benchmarkinstitute.org/t_by_t/mcle/sa.pdf [reviewed 2020.08.20].

28. Allan RB. Alcoholism, Drug Abuse and Lawyers: AreWe Ready to Address the Denial? Creighton Law Review. 1998;31:265-277.

29. Goldstein C. The Role of Alcoholism in Judicial Discipline Decisions. Loyola University Chicago Law Journal. 1985;16:549-588.

30. Ri'shennya Vishhoyi radi pravosuddya vi'd 22.05.2020 №1472/1dp/1520. [Decision by the Highest Council of Justice dated 22.05.2020 №1472/1dp/15-20] Available from: https://hcj.gov.ua/doc/doc/3124 [reviewed 2020.08.18] (Ua).

ORCID and contributionship:

Oksana Z. Khotynska-Nor: 0000-0002-4480-6677 A,B,D

Lidiya M. Moskvych:0000-0001-7339-3982 E,F

\section{Conflict of interest:}

The Authors declare no conflict of interest.

\section{CORRESPONDING AUTHOR Lidiia M. Moskvych \\ Yaroslav Mudryi National Law University, Kharkiv, Ukraine \\ Pushkinskaya str., 77, 61024 Kharkiv, Ukraine \\ tel: +380500544485 \\ e-mail:moskvichlida@gmail.com}

Received: 31.08 .2020

Accepted: 30.11 .2020

A - Work concept and design, B - Data collection and analysis, C - Responsibility for statistical analysis, D-Writing the article, $\mathbf{E}$-Critical review, $\mathbf{F}$ - Final approval of the article 